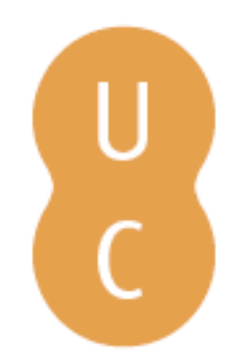

\title{
nombalina
}

\section{Educação em tempos de humanidades digitais: algumas aproximações}

Autor(es): Dias-Trindade, Sara; Mill, Daniel

Publicado por: Imprensa da Universidade de Coimbra

URL

persistente: URI:http://hdl.handle.net/10316.2/47408

DOI: $\quad$ DOl:https://doi.org/10.14195/978-989-26-1772-5_0

Accessed : $\quad$ 26-Apr-2023 10:19:36

A navegação consulta e descarregamento dos títulos inseridos nas Bibliotecas Digitais UC Digitalis, UC Pombalina e UC Impactum, pressupõem a aceitação plena e sem reservas dos Termos e Condições de Uso destas Bibliotecas Digitais, disponíveis em https://digitalis.uc.pt/pt-pt/termos.

Conforme exposto nos referidos Termos e Condições de Uso, o descarregamento de títulos de acesso restrito requer uma licença válida de autorização devendo o utilizador aceder ao(s) documento(s) a partir de um endereço de IP da instituição detentora da supramencionada licença.

Ao utilizador é apenas permitido o descarregamento para uso pessoal, pelo que o emprego do(s) título(s) descarregado(s) para outro fim, designadamente comercial, carece de autorização do respetivo autor ou editor da obra.

Na medida em que todas as obras da UC Digitalis se encontram protegidas pelo Código do Direito de Autor e Direitos Conexos e demais legislação aplicável, toda a cópia, parcial ou total, deste documento, nos casos em que é legalmente admitida, deverá conter ou fazer-se acompanhar por este aviso.

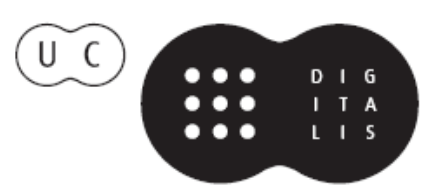




\section{EDUCAÇÃO E}

\section{HUMANIDADES}

IMPRENSA DA

UNIVERSIDADE

DE COIMBRA

COIMBRA

UNIVERSITY

DIGITAIS

APRENDIZAGENS,

TECNOLOGIAS E

CIBERCULTURA

SARA DIAS-TRINDADE DANIEL MILL

(ORGS.)

की
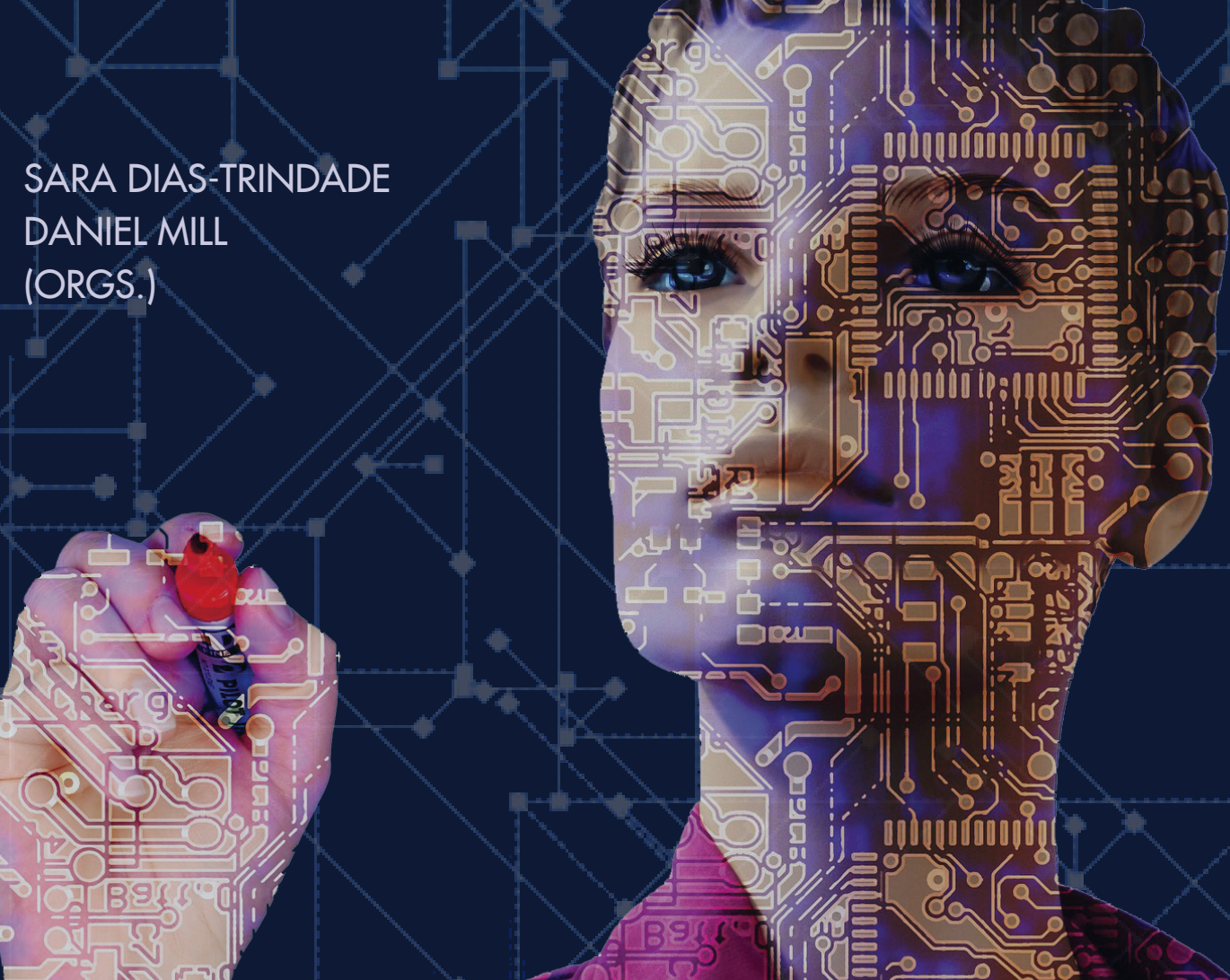
SARA DIAS-TRINDADE

Departamento de História, Estudos Europeus, Arqueologia e Artes - Faculdade de Letras da Universidade de Coimbra

Centro de Estudos Interdisciplinares do Século XX - Universidade de Coimbra

ORCID: https://orcid.org/0000-0002-5927-3957

DANIEL MILL

Universidade Federal de São Carlos

Centro de Estudos Interdisciplinares do Século XX - Universidade de Coimbra

ORCID: https://orcid.org/0000-0002-8336-3645

\section{E D UCAÇ ÃO EM TEMPOS DE HUMANIDADES \\ D I G ITA I S: ALGUMASAPROXIMAÇÕ ES}

\section{Considerações iniciais sobre a relação entre Educação e Humanidades Digitais}

O mundo educacional está diferente, a Escola vê-se perante novos públicos, novas necessidades, novas possibilidades. Surge uma nova visão da educação, que busca nos seus estudantes o desenvolvimento de competências variadas, interdisciplinares, adequadas às demandas deste milénio em que nos encontramos. Quase num retorno ao Homem de Vitrúvio, completo, de formação geral e transdisciplinar, querem-se hoje, nos estudantes, cidadãos com uma formação que efetivamente promova não só o desenvolvimento das literacias fundacionais, mas também qualidades de caráter e competências-chave (WEF, 2015).

Todavia, esta Escola encontra no seu público-alvo um grupo habituado a movimentar-se de forma fluida por espaços híbridos, multimodais e ubíquos, num verdadeiro nomadismo digital, sempre ligados, sempre em rede, construindo desta forma o seu conhecimento, num nível de convergência que se refere "às conexões profundas e complexas, criadas num nível cognitivo de percepção dos indivíduos, considerando o seu estado ubíquo de acesso e 
navegação dentro de diferentes ambientes físicos e virtuais" (Moreira; Dias-Trindade, 2018, pp. 68-69).

Neste contexto, a ligação entre a Educação e as Humanidades Digitais faz todo o sentido, sobretudo pelo facto de que estas promovem

o desenvolvimento de competências de pensamento crítico, de abordagens complexas do passado e do presente através dos seus quadros interpretativos, associados a uma utilização "em contexto" da tecnologia, numa ótica já não de mera utilização acrítica de ferramentas, mas antes da sua adaptação ou criação como forma de potenciar o conhecimento (Ribeiro; Trindade, 2017, p. 149).

De facto, e apesar de não existir unanimidade na definição das Humanidades Digitais, o entendimento sobre o que será o seu foco parece claro: contribuir para que os estudantes desenvolvam um conjunto de competências tecnológicas, sociais, culturais e intelectuais para terem sucesso no seu futuro (Presner; Johanson, 2009). Merece aqui o destaque de que este estudante, nômade digital, vive de tal forma cercado de tecnologia, imerso em plataformas e mundos diversificados que se sente confortável no uso constante de diferentes tecnologias digitais, mas por vezes tem dificuldades em orientar esses conhecimentos em favor das suas próprias aprendizagens. Cabe à escola e aos seus professores a capacidade para reconhecer esta nova tipologia de estudante e reverter em benefício desse mesmo estudante aquelas que são as suas competências sociais. A Escola tem de

aprender a lidar com a observação distraída, que proporciona aprendizagens na diversão; com as aprendizagens construídas no contato com novas linguagens, criando ambientes que possibilitem que as narrativas reflitam as identidades locais e grupais; com percepções da cultura como híbridos de relações múltiplas (Sartori, 2010, pp. 46-47).

Nesse contexto, é claramente importante a utilização das tecnologias digitais - de modo planejado e estruturado -, de forma a que o seu impacto pedagógico se veja refletido na qualidade da aprendizagem (Mill, 2010, 2013). Conforme Trindade e Moreira (2017), a investigação tem sublinhado a ideia da dimensão pedagógica da utilização da tecnologia e o seu impacto na forma 
como o estudante aprende, como o professor ensina e como a instituição entende a sua utilização como suporte ao processo educativo e/ou como mediação comunicacional entre os sujeitos aí envolvidos.

A perspectiva de uma aprendizagem individualizada, de flexibilidade pedagógica, surge num contexto em que se reconhece que a interação entre estratégias de ensino inovadoras e as tecnologias digitais fomenta ambientes de aprendizagem mais ricos e mais adequados às necessidades de cada um dos nossos estudantes (Dias-Trindade; Carvalho, 2019). Nesse mesmo contexto, temos experimentado o desenvolvimento de espaços de aprendizagem em rede, permitindo a partilha de conteúdos - um fruto da cultura digital, da cibercultura. Conforme Paulo Dias (2013, p. 5), um dos resultados da globalização das práticas de comunicação e da experiência do conhecimento na sociedade digital é a emergência de nova noção de proximidade social e cognitiva nos processos educacionais, em que a distância deixa de constituir um limite no acesso à educação e à aprendizagem.

Por isso, é importante explorar as tecnologias digitais de informação e comunicação (TDIC) para desenvolver ambientes de aprendizagem em que os interesses e as necessidades dos estudantes se interliguem, concorrendo para o desenvolvimento de competências importantes e imprescindíveis para o sucesso na Era Digital em que vivemos (Dias-Trindade, 2018). Nesse sentido, estudos indicam que

essas tecnologias digitais criaram condições favoráveis para experiências diferenciadas e novas noções em relação ao lugar/espaço e ao horário/momento/tempo de socialização, com implicações plurais, de natureza cultural, social, política, ambiental, geográfica, artística, trabalhista etc. (Mill, 2015, p. 410).

A incorporação de tecnologias (especialmente as digitais) no contexto educacional relaciona-se diretamente com as transformações culturais que a escola ainda carece de viver. Conforme argumentou Lévy (1999, p. 63), os maiores portadores de mutações culturais são os novos dispositivos informacionais (caracterizados pelos mundos virtuais) e comunicacionais (marcados pela partilha ou comunicação coletiva ou todos-todos). Por isso, normalmente "a incorporação de novas práticas pedagógicas ou a reformulação de procedi- 
mentos tradicionais de ensino-aprendizagem se efetiva a partir de mudanças de mentalidade e de mutações culturais" (Mill, 2013, p. 20). Isto é, a cibercultura fomenta transformações e mutações essenciais para o contexto educacional dessa nova época, que experimentamos ao final desta segunda década do século XXI. Ademais, sabemos que "todo processo educacional baseia-se na socialização de conhecimentos, que por sua vez envolve intenso processo comunicacional para sensibilização sociocultural, de comportamento e valores, mudanças intelectuais e emocionais" (Mill et al., 2018, p. 7).

Enfim, buscando contribuições para esta reflexão entre Educação e Tecnologias, reunimos aqui um conjunto de textos com considerações sobre o assunto. Num esforço didático, agrupamos os capítulos em dois blocos, sendo o primeiro deles composto de oito (8) reflexões voltadas para a aprendizagem no contexto das humanidades digitais. No segundo bloco, temos sete (7) capítulos, em que os autores discutem as tecnologias digitais em contextos educacionais, apresentando experiências, propostas e possibilidades de incorporação de dispositivos no seio educacional.

\section{Reflexões propositivas e desafios para a aprendizagem no contexto das humanidades digitais}

Alguns autores caracterizam as Humanidades Digitais como interdisciplinares, colaborativas, socialmente engajadas, globais, oportunas e relevantes, assumindo que estas "ensinam os estudantes a desenvolver competências ao nível do pensamento crítico, das literacias dos media, bem como competências tecnológicas fundamentais para o sucesso na Era da informação digital" (Presner; Johanson, 2009, p. 4, tradução nossa). ${ }^{1}$ Nesses tempos em que o digital tem assumido posição privilegiada (e de controle), parece-nos essencial perceber as suas vantagens e conhecer melhor as suas limitações e desvantagens. Somente assim podemos explorar as potencialidades dessas tecnologias digitais e conceber estratégias de aprendizagens cada vez

${ }^{1}$ No original: "teaches students the critical thinking skills, media literacies, and technical knowledge necessary for success in the digital information age". 
mais profícuas e motivantes. Nessa perspectiva, é necessário também compreender: como é que, em contexto das Humanidades Digitais, se podem desenvolver cenários pedagógicos transformadores, em que as aprendizagens promovam o desenvolvimento de competências diversificadas, fundamentais para o sucesso neste milênio?

Com esta questão como norte, o conjunto de textos que compõem esta primeira parte da obra (Aprendizagem no contexto das Humanidades Digitais: reflexões, caminhos e desafios contemporâneos) dá atenção às aprendizagens no contexto das Humanidades Digitais. Nos próximos parágrafos, apresentamos sinteticamente os capítulos do primeiro bloco deste livro.

No primeiro texto, Luciano Gamez nos apresenta os "Desafios à concepção e implementação de cenários pedagógicos digitais em sistemas de aprendizagem a distância”, abordando o projeto ou desenho de processos educacionais em ambientes digitais. Considerando o método MISA (Méthode d'Ingénierie d'un Systéme d'Apprentissage), desenvolvido por Gilbert Paquette, o capítulo analisa a interseção entre o desenho pedagógico, a engenharia de software e a engenharia cognitiva. Para Luciano Gamez, o método MISA é boa estratégia para apoiar a concepção e implementação de cenários pedagógicos e sistemas de aprendizagem, especialmente quando consideramos o grande leque de possibilidades, não somente sobre o plano das estratégias pedagógicas e das mídias digitais, mas também na escolha dos recursos tecnológicos de comunicação e dos modos de transmissão. No texto, o conjunto de elementos necessários ao planejamento de um cenário pedagógico é abordado pela aproximação do designer educacional ao contexto em que a situação formativa ocorre, a fim de adaptar o sistema de aprendizagem às características dos seus usuários, baseando-se em princípios e métodos da Ergonomia Cognitiva e da análise da tarefa para conceber e implementar novos cenários de ensino e aprendizagem.

Wilsa Maria Ramos e Cintia Inês Boll trazem-nos o texto sobre "A cultura digital e os novos contextos de aprendizagem: quem sabe como e onde eu aprendo sou eu", explicando que o uso intensivo e globalizado de diversos recursos multimídias disruptivos e ao mesmo tempo adaptativos à necessidade humana tem sido o portal de entrada para a criação de uma nova ecologia da aprendizagem, resultado de mudanças nas trajetórias pessoais de aprendizagem, como via de acesso ao conhecimento na sociedade da informação. 
As autoras reiteram que o uso intensivo e globalizado da cultura digital é um pano de fundo apropriado para discutir como esses processos de mudanças têm repercutido no olhar pedagógico e discutem, por isso, as possibilidades e oportunidades advindas da cultura digital, que dão um novo contorno aos contextos de aprendizagem, caracterizando as tendências e escolhas de rotas para a construção de conhecimentos denominadas de novas ecologias. Para além disso, deixam-nos também exemplos de projetos para que as escolas possam apoiar a formação de aprendizes sensíveis culturalmente e capazes de atribuir sentido ao seu processo de aprendizagem.

Sara Dias-Trindade e J. António Moreira apresentam-nos o texto "Da literacia à fluência: como avaliar o nível de proficiência digital de professores?", refletindo sobre a vivência numa Era Digital, em que o real e o virtual se confundem cada vez mais, mas também na qual ainda existe um longo caminho a percorrer no que diz respeito à integração das tecnologias digitais em ambientes educativos. Consideram os autores que é fundamental que os docentes percebam como usar essas tecnologias para criar cenários sustentáveis de aprendizagem nos quais as estratégias de ensino fazem uso do digital para criar ambientes motivadores e criativos. Neste contexto, descrevem o questionário elaborado pelo EU Science Hub, DigCompEduCheckIn, o qual permite aos docentes perceber quais as suas competências quanto ao uso educativo das tecnologias digitais e sugere novas estratégias para ultrapassar as dificuldades existentes e alcançar aquilo que poderá ser uma verdadeira fluência digital, ou seja, não só fazer uso das tecnologias digitais, mas compreender quando é que esse uso é efetivamente rentável para atingir os objetivos desejados.

O texto de Adriana Rocha Bruno, Lucila Pesce e Ana Maria Di Grado Hessel, intitulado "Educação Aberta e Cultura digital: humanidades em autoria e diálogo nos processos formativos", abre um debate sobre a potência das humanidades digitais para a construção de processos formativos mais significativos aos sujeitos sociais em formação, destacando os conceitos de autoria, diálogo e Educação Aberta. Nesse sentido, as autoras dão atenção à formação de professores, considerando a perspectiva culturalista, a potência da linguagem hipermidiática da cibercultura e os aspectos afeitos à Educação Aberta. Partindo de uma experiência que vivenciaram, as autoras sinalizam as potencialidades da prática da Educação Aberta na cultura digital e as 
possibilidades que as humanidades digitais oferecem ao estabelecimento do diálogo, da autoria e da ampliação da perspectiva de alteridade na formação docente.

A autora Cláudia Coelho Hardagh, com o texto "A Pedagogia Digital e Maker como caminho para mente expandida", analisa o território da escola e sua relação com a Cultura Digital. O território escolar em questão limita-se ao Brasil, cidade de São Paulo, da perspectiva do curso de Pedagogia em instituição particular e escolas públicas da periferia. Partindo da análise de documentos oficiais, questionários aplicados no curso de Pedagogia e projetos de extensão para escolas públicas, o estudo fundamenta-se na epistemologia interdisciplinar, com eixo nas áreas de sociologia, pedagogia e história da cultura, para construir um marco teórico da Pedagogia Digital e Maker. Partindo do pressuposto de que não há o habitus da Cultura Digital na cultura escolar, a autora sugere - como alternativa a esse descompasso cultural - a inserção da Pedagogia Digital e Pedagogia Maker em territórios escolares como um dos caminhos para romper a ignorância cognitiva e digital. Para alcançar tais objetivos, propõe-se potencializar o diálogo entre professores e alunos, ambos na posição de aprendentes, trazendo a reflexão para a inserção do habitus digital na práxis do professor (e dos estudantes, por conseguinte).

No texto "Da linguagem logo aos espaços de convivência híbridos e multimodais: percursos da formação docente em educação na cultura digital", a autora Eliane Schlemmer parte das memórias profissionais de sua trajetória formativa na área da Educação Digital, buscando tecer a historicidade da Informática na Educação no Brasil, na relação com os percursos da formação docente vinculados às Tecnologias Digitais (TD), e que tem início com a linguagem e filosofia Logo, na década de 1970. Nesse processo, vivências, memórias e reflexões são articuladas num movimento que busca compreender os desafios, as mudanças e, inclusive, algumas transformações e inovações que permitem referências ao desenvolvimento de fluência técnico-didático-pedagógica. Assim, a autora avança no entendimento do "uso de" TD na educação para a compreensão da "apropriação para”, em que o aplicar dá lugar ao desenvolver, em uma proposta que explicita as quatro dimensões (4D) da formação docente em tempos de humanidades digitais. 
No seu texto "Transitando entre gêneros musicais: aproximações entre a escola e os meios digitais por meio da apreciação musical", Paulo Constantino explica-nos como a música - em especial, os gêneros musicais - em paralelo com as tecnologias se podem aproximar da escola contemporânea na educação básica. Explica Constantino que, neste percurso, o envolvimento dos alunos com as atividades educacionais e sua ambientação às virtualidades poderá ser ampliado pela apreciação musical, constituindo-se em aspecto a ser relevado na formação docente. A apreciação da música é certamente uma das atividades mais persistentes na rotina das crianças, adolescentes e jovens. Os meios digitais potenciaram este comportamento, elevando-o a um patamar sem precedentes históricos. Nesse sentido, torna-se importante debater as relações entre música e tecnologias na escola para lançar luz sobre múltiplos aspectos, fazendo emergir os contextos e funções que a música pode assumir na escola e nos ambientes virtuais.

Gláucia Maria dos Santos Jorge traz-nos uma reflexão sobre "Geração digital: o que os youtubers mirins do Brasil têm a dizer sobre raça, gênero e classes sociais". Neste texto a autora nos apresenta uma reflexão sobre como os mais jovens estão representando estes conceitos, a partir dos resultados obtidos com uma pesquisa qualitativa de base etnográfica, desenvolvida na Universidade Federal de Ouro Preto (UFOP). Foram analisados vídeos produzidos por três youtubers mirins brasileiros em que encenam situações vivenciadas no salão de beleza, considerando-se dois aspetos: o protagonismo das crianças na produção e o número de visualizações que eles alcançaram. As conclusões indicam que os youtubers mirins comunicam diretamente a outras crianças, inseridas nas culturas digitais, padrões preestabelecidos de beleza, comportamentos estereotipados de classes sociais e a adultização da infância.

Além desses textos apresentados até aqui, que compõem a primeira parte da obra, envolvendo reflexões e proposições em torno da aprendizagem no contexto das Humanidades Digitais, preparamos um segundo bloco de discussões para este livro. Conforme se observa na próxima seção, esta segunda parte tem foco em propostas e experiências que fazem uso de tecnologias digitais em contextos educacionais. 


\section{Experiências, propostas e possibilidades do uso das tecnologias digitais em contextos educacionais}

As possibilidades geradas pelas Tecnologias Digitais permitem o desenvolvimento de diferentes experiências pedagógicas. Todavia, é importante destacar o facto de que a total fruição dessas possibilidades passa por iniciativas de incorporação de artefatos e estratégias relacionadas às tecnologias digitais de informação e comunicação. Nesse sentido, também "podemos conseguir complementar as pedagogias e metodologias já existentes com novas estratégias focadas em projetos, pesquisas ou métodos de aprendizagem adaptativos" (Dias-Trindade; Moreira, 2018, p. 641). Percebe-se claramente que o caráter inovador dessas pedagogias ou metodologias emergentes decorre do potencial das tecnologias digitais para desenvolver experiências e propostas para diferentes cenários educativos, procurando dar corpo, de forma estruturada e crítica, ao principal elemento desse processo: a aprendizagem dos sujeitos envolvidos.

Já há algum tempo, autores como Litwin (2001), Fantin e Rivoltella (2013), Mill (2010, 2013), Selwyn (2014, 2017), Ferreira, Rosado e Carvalho (2017), entre outros, indicam e ressaltam aspectos decorrentes das tecnologias de informação e comunicação que já não podem ser ignorados nas reflexões e experiências sobre o ensino-aprendizagem, especialmente quando desejamos considerar a qualidade das práticas pedagógicas.

A Educação, assim como outras agências sociais, está submetida às condições do contexto e forças externas a ela. Nesse sentido, a escola, a universidade e os sujeitos envolvidos no processo educacional vêm experimentando influência direta das transformações sociais mais recentes, entre elas destaca-se o acelerado processo de desenvolvimento tecnológico (Mill et al., 2018, p. 15).

Emergem, assim, o desafio e a importância de conceber e implementar práticas pedagógicas criativas e estratégias de ensino-aprendizagem inovadoras. Nesta perspectiva, apresentamos a seguir as contribuições dos textos da segunda parte da presente obra, em que os autores anunciam experiên- 
cias, propostas e possibilidades do uso das tecnologias digitais em contextos educacionais.

No texto "Mapas conceituais como estratégia inovadora na formação de professores no paradigma da complexidade", as autoras Patrícia Lupion Torres, Marilda Aparecida Behrens e Ariana Cosme apresentam uma reflexão sobre a relação entre novas possibilidades de ensinar e aprender e a necessidade de buscar processos inovadores de formação continuada de professores. Na discussão sobre a formação de professores nesse século XXI, as autoras acolhem o paradigma da complexidade (Morin, 2000), argumentando que ele desafia a pensar e viver contemplando múltiplas tendências, considerando as conquistas das diferentes eras oral, escrita e digital. O entendimento central do texto é que, no contexto da cultura digital, a formação continuada de professores necessita considerar que as tecnologias emergentes podem auxiliar em novas propostas para docência num paradigma inovador. Nesse sentido, defendem a utilização da tecnologia com todo seu espectro, mas destacando as funcionalidades do software CmapTools para o processo de elaboração de mapas conceituais - entendidos como ricas ferramentas de auxílio na transformação de informações em conhecimento de maneira crítica e reflexiva.

Cintia Inês Boll, Margarete Axt e Daniel Nehme Muller refletem sobre "Aplicativos mobile pedagógicos para a Educação Básica: da possibilidade dialógica para uma inteligência conectiva", por meio de uma perspectiva da potência criadora deliberadamente alocada para conectar usuários na ação comunicativa e de aprendizagem. Os autores explicam quem são os envolvidos neste processo: de um lado, os desenvolvedores destes aplicativos, chamados de appers pedagógicos, definindo que modelos eles seguem e como estruturam a estética das suas criações, e, do outro, os estudantes-usuários ou atratores, que num processo enunciativo se relacionam com a ideia de que, além de serem indivíduos coletivos, são "multivíduos". Boll, Axt e Muller apresentam o resultado desta interação entre desenvolvedores e usuários, demonstrando que essa carga ativada na relação com o usuário por meio do aplicativo (app) pode ser entendida como inteligência conectiva, existindo em potência na criação, mas sendo vivida apenas na relação discursiva dialógica.

Explorando a "Robótica Pedagógica como meio de engajamento do estudante: algumas aproximações”, Ortenio Oliveira e Daniel Mill apresentam a 
robótica como estratégia potencial para atender às demandas da área educacional. Marcada por um forte discurso em torno de seu potencial de inovação e de motivação do estudante, a robótica pedagógica instala-se como metodologia ativa para o aprendizado de diversos conteúdos curriculares, de modo multi e interdisciplinar, e para a constituição de ambientes de aprendizagem mais engajada. Nesse contexto, objetivando analisar a construção do conhecimento por meio da robótica, o presente trabalho apresenta a identificação e observação de duas experiências. Relacionando a robótica e as teorias construtivista (Jean Piaget), sociointeracionista (Lev Vygotsky) e construcionista (Seymour Papert), os autores explicam que a montagem dos dispositivos, sua programação e testes auxiliam no desenvolvimento psicomotor, cognitivo e afetivo dos alunos, especialmente em função do seu potencial de socialização (sentimento de pertença, interesse, engajamento, envolvimento e colaboração).

Outra importante contribuição desta obra é o texto "A educação matemática mediada pelas tecnologias digitais: o uso da programação de computadores como estratégia didática”, de autoria de Valéria Espíndola Lessa, Adriano Canabarro Teixeira e Daniela Melaré V. Barros. Analisando tal temática, o texto apresenta resultados de uma investigação de doutorado com interesse nos processos de representação e de compreensão do campo conceitual da matemática para estudantes da educação básica. Considerando um ambiente de programação de computadores para crianças (Scratch 2.0), os autores do texto indicam necessidade de reformulação das estratégias didáticas mais tradicionais, adotadas no ensino de matemática, considerando as condições contextuais da cultura digital e as tecnologias de informação e comunicação típicas da nossa época. Também vale destacar as contribuições que os autores buscam na teoria dos estilos de aprendizagem para fomentar estratégias didáticas diferenciadas e mais coerentes com a cultura digital. Um dos argumentos centrais do texto está no potencial das tecnologias digitais (como o Scratch 2.0) para a melhoria da qualidade do processo de ensino e aprendizagem no campo da educação matemática.

Glauber Lúcio Alves Santiago e Camila Dias de Oliveira, por sua vez, com o texto "Movimento maker e IoT para educação musical: possibilidades com Impressão 3D, software Processing e Arduino", incentivam o docente não só 
de música, mas de todas as áreas da educação a aderir ao movimento maker e considerar a Internet das Coisas (IoT) entre as possibilidades de criação de estratégias de ensino-aprendizagem. Depois de definir estes dois conceitos, os autores descrevem três grandes tecnologias a serem utilizadas neste contexto, sempre buscando deixar o texto o mais acessível possível para o público leigo nestas tecnologias. Então, tem lugar a apresentação sobre a Impressão 3D, a linguagem e IDE Processing e o Arduino. Em seguida, são apresentadas 14 categorias de ideias de uso para educação musical no contexto do movimento maker e da IoT. No capítulo, também são indicados caminhos que o professor pode percorrer para se empoderar dessas tecnologias no seu dia a dia profissional.

No capítulo "Aprendizaje informal con mods en videojuegos", Ruth S. Contreras-Espinosa e Jose Luis Eguia-Gomez procuram definir uma parte de um fenómeno que não é novo, mas que ainda se encontra em construção: o modding. Este conceito reporta-se a uma forma de produção em que os jogadores experimentam desenvolvendo e conceptualizando o seu trabalho. Os papéis são mistos, porque os participantes se envolvem numa grande diversidade de práticas em colaboração contínua. Neste estudo, os autores identificam algumas das motivações, práticas diárias e papéis adotados por um grupo de 40 estudantes do Ensino Superior em Barcelona que fazem modificações em videojogos, dando especial atenção às consequências da participação e da aprendizagem informal alcançada. Os resultados da pesquisa, baseada num estudo etnográfico realizado em 2014, mostram o objetivo perseguido pelos modders (finalizar complementos ou mods), quais são suas motivações (pesquisa, autoexpressão ou cooperação) e a aprendizagem informal obtida pelos participantes (rendimento e desempenho de habilidades, trabalho em equipe ou resolução de problemas).

Por seu turno, o capítulo "Anatomia de um Crime: cruzando Comunicação e Ciências Físicas e Químicas", de autoria de Marisa Correia e Teresa Maia e Carmo, relata uma atividade interdisciplinar de base digital, realizada no âmbito da formação de professores, entre as unidades curriculares Comunicar em Língua Portuguesa (CLP) e Ciências Físicas e Químicas (CFQ) da licenciatura em Educação Básica na Escola Superior de Educação do Instituto Politécnico de Santarém. Partindo do interesse recente pela ciência forense, 
muito estimulado e potenciado pela abundância de séries televisivas em que o assunto é central, as autoras desenvolveram uma atividade didática que consistiu na investigação de um caso fictício de homicídio. O exercício, que decorreu em várias plataformas digitais e envolveu desafios para discentes e docentes, permitiu refletir sobre algumas das questões que hoje se colocam com mais acuidade no processo de formação de futuros professores em interação com as Humanidades Digitais. Como conclusão, as autoras denunciam a inadequação dos atuais instrumentos de ensino superior, desarticulados ou incoerentes com os seus destinatários, pois ainda carecemos de estratégias de uso pedagógico das tecnologias digitais de informação e comunicação.

\section{Considerações finais}

No cenário de cultura digital em que vivemos atualmente, entendemos ser essenciais reflexões e proposições em torno das potencialidades pedagógicas das mais recentes tecnologias telemáticas. Em geral, as pessoas já experimentam aplicativos e dispositivos digitais em diversas situações cotidianas, sem, contudo, explorar tais tecnologias em situações de aprendizagem formal. Nesse sentido, ao organizarmos esta obra, investimos esforços para contribuir com a articulação entre Educação e Tecnologias, seja em termos teóricos e de reflexões (Parte 1) ou em termos práticos e de propostas (Parte 2).

Nossa proposta, neste livro, é apresentar ao leitor um conjunto de textos voltados aos interesses de quem pensa ou faz educação de qualidade, explorando as potencialidades das tecnologias emergentes. Acreditamos que temos aqui, portanto, uma obra com contribuições primorosas para o processo de ensino-aprendizagem contemporâneo. Fica o convite à navegação, pelas linhas e entrelinhas registradas nas páginas deste livro. Boa leitura!

\section{Referências bibliográficas}

DIAS, P. - Inovação pedagógica para a sustentabilidade da educação aberta e em rede. Educação, Formação \& Tecnologias. Lisboa. ISSN 1646-933X. 6:2 (2013) 4-14. 
DIAS-TRINDADE, S. - Ambientes digitais de aprendizagem, comunidades de prática e dispositivos móveis. In MILL, D. [et al.] (Orgs.) - Educação e Tecnologias: reflexões e contribuições teórico-práticas. São Carlos: EdUFSCar, 2018. ISBN 978-85-6480317-6. p. 95-106.

DiAS-TRINDADE, S.; CARVAlHO, J. R. - História, Tecnologias Digitais e Mobile Learning. Coimbra: Imprensa UC, 2019. No prelo.

DIAS-TRINDADE, S.; MOREIRA, J. A. - Avaliação das competências e fluência digitais de professores no ensino público médio e fundamental em Portugal. Revista Diálogo Educacional. Curitiba. eISSN 1981-416X. 18:58 (2018) 624-644.

FANTIN, M.; RIVOLTELLA, P. C. - Cultura digital e escola: pesquisa e formação de professores. Campinas: Papirus, 2013. ISBN 978-85-3080-963-8.

FERREIRA, G. M. S.; ROSADO, L. A. S.; CARVAlHO, J. S. (Orgs.) - Educação e tecnologia: abordagens críticas. Rio de Janeiro: Unesa, 2017. ISBN 978-85-5548-465-0.

LÉVY, P. - Cibercultura. São Paulo: Editora 34, 1999. ISBN 978-85-7326-126-4.

LITWIN, E. (Org.) - Tecnologia educacional: política, histórias e propostas. Porto Alegre: Artmed, 2001. ISBN 978-85-7307-232-7.

MILL, D. - Das inovações tecnológicas às inovações pedagógicas: considerações sobre o uso de tecnologias na educação a distância. In MILL, D.; PIMENTEL, N. (Orgs.) Educação a distância: desafios contemporâneos. São Carlos: EdUFSCar, 2010. ISBN 978-85-7600-215-4. p. 43-57.

_ Gestão estratégica de sistemas de educação a distância no Brasil e em Portugal: a propósito da flexibilidade educacional. Educação Social. Campinas. ISSN 16784626. 36:131 (Abr./Jun. 2015) 407-426.

_ Mudanças de mentalidade sobre educação e tecnologias: inovações e possibilidades tecnopedagógicas. In MILL, D. (Org.) - Escritos sobre Educação: desafios e possibilidades para ensinar e aprender com tecnologias contemporâneas. São Paulo: Paulus, 2013. ISBN 978-85-3493-372-8. p. 11-38.

MILL, D. [et al.] - Reflexões e práticas sobre Educação e Tecnologias: uma apresentação. In Mill, D., SANTIAGO, G.; SANTOS, M.; PINO, D. (Orgs.) - Educação e Tecnologias: reflexões e contribuições teórico-práticas. São Paulo: Artesanato Educacional, 2018. ISBN 978-85-6480-317-6. p. 7-16.

MOREIRA, J. A.; DIAS-TRINDADE, S. - Tablets e o instinto nômade do estudante da era digital. In CARDOSO, A. L.; SANTOS, A. G.; SANTO, E. E. (Orgs.) - Tecnologias e Edu- 
cação Digital: Diálogos Contemporâneos. Cruz das Almas: Universidade Federal do Recôncavo da Bahia, 2018. ISBN 978-85-5971-044-1. p. 67-90.

MORIN, E. - Os sete saberes necessários à educação do futuro. São Paulo: Cortez; Brasília: Unesco, 2000. ISBN 978-85-249-0741-x.

PRESNER, T.; JOHANSON, C. - The Promise of Digital Humanities: A Whitepaper [Em linha]. 2009. [Consult. 20 Out. 2018]. Disponível em WWW: <URL: http://www.itpb. ucla.edu/documents/2009/PromiseofDigitalHumanities.pdf>.

RIBEIRO, A. I.; TRINDADE, S. D. - O ensino da História e tecnologia: conexões, possibilidades e desafios no espaço das Humanidades Digitais. In PORTO, C.; MOREIRA, J. A. (Coord.) - Educação no ciberespaço: Novas configurações, convergências e conexões. Aracaju: Editora Universitária Tiradentes, 2017. ISBN 978-989-8765-53-6. p. $145-159$.

SARTORI, A. - Educomunicação e sua relação com a escola: a promoção de ecossistemas comunicativos e a aprendizagem distraída. Comunicação, Mídia e Consumo. São Paulo. ISSN 1983-7070. 7:19 (Jul. 2010) 33-48.

SELWYN, N. - Educação e Tecnologia: questões críticas. Trad. de Giselle M. S. Ferreira. In FERreira, G. M. S.; ROSADO, L. A. S.; CARVAlHO, J. S. (Orgs.) - Educação e tecnologia: abordagens críticas. Rio de Janeiro: Unesa, 2017. ISBN 978-85-5548-465-0. p. 85-103.

SELWYN, N.; FACER, K. - The sociology of education and digital technology: Past, present and future. Oxford Review of Education. Londres. ISSN 0305-4985. 40(4) (Jul. 2014) 482-496.

TRINDADE, S. D.; MOREIRA, J. A. - Competências de aprendizagem e tecnologias digitais. In MOREIRA, J. A.; VIEIRA, C. P. (Coords.) - eLearning no Ensino Superior. Coimbra: Centro de Inovação e Estudo da Pedagogia no Ensino Superior (Cinep), 2017. ISBN 978-989-99463-4-7. p. 99-116. (Coleção Estratégias de Ensino e Sucesso Académico: Boas Práticas no Ensino Superior).

WEF (World Economic Forum) - New Vision for Education: Unlocking the Potential of Technology. Cologny/Geneva: World Economic Forum, 2015. 